\title{
Sarcocysts of an Unidentified Species of Sarcocystis in the Sea Otter (Enhydra lutris)
}

\author{
Author(s): J. P. Dubey , D. S. Lindsay , B. M. Rosenthal , and N. J. Thomas
}

Source: Journal of Parasitology, 89(2):397-399. 2003.

Published By: American Society of Parasitologists

DOI: http://dx.doi.org/10.1645/0022-3395(2003)089[0397:SOAUSO]2.0.CO;2

URL: http://www.bioone.org/doi/full/10.1645/0022-3395\%282003\%29089\%5B0397\%3ASOAUSO

$\% 5 \mathrm{D} 2.0 . \mathrm{CO} \% 3 \mathrm{~B} 2$

BioOne (www.bioone.org) is a nonprofit, online aggregation of core research in the biological, ecological, and environmental sciences. BioOne provides a sustainable online platform for over 170 journals and books published by nonprofit societies, associations, museums, institutions, and presses.

Your use of this PDF, the BioOne Web site, and all posted and associated content indicates your acceptance of BioOne's Terms of Use, available at www.bioone.org/page/terms_of_use.

Usage of BioOne content is strictly limited to personal, educational, and non-commercial use. Commercial inquiries or rights and permissions requests should be directed to the individual publisher as copyright holder. 
American Society of Parasitology. J. P. Dubey, D. S. Lindsay, B. M. Rosenthal, and N. J. Thomas (2003). "Sarcocysts of an Unidentified Species of Sarcocystis in the Sea Otter (Enhydra lutris)," Journal of Parasitology, Vol. 89, No. 2, pp. 397-399. doi: http:// dx.doi.org/10.1645/0022-3395(2003)089[0397:SOAUSO]2.0.CO;2

\title{
Sarcocysts of an Unidentified Species of Sarcocystis in the Sea Otter (Enhydra lutris)
}

\begin{abstract}
J. P. Dubey, D. S. Lindsay*, B. M. Rosenthal, and N. J. Thomas†, Parasite Biology, Epidemiology and Systematics Laboratory, Animal and Natural Resources Institute, Agricultural Research Service, United States Department of Agriculture, Building 1001, Beltsville, Maryland 207052350. e-mail: jdubey@anri.barc.usda.gov. *Department of Biomedical Sciences and Pathobiology, Center for Molecular Medicine and Infectious Diseases, Virginia-Maryland Regional College of Veterinary Medicine, Virginia Tech, 1410 Prices Fork Road, Blacksburg, Virginia 24061-0324. †Department of the Interior, United States Geological Survey, National Wildlife Health Center, 6006 Schroeder Road, Madison, Wisconsin 53711
\end{abstract}

ABSTRACT: The number of Sarcocystis species that infect sea otters (Enhydra lutris) is unknown. Sea otter tissues were recently shown to harbor sarcocysts of $S$. neurona and of unidentified species of Sarcocystis. Whereas sarcocysts of $S$. neurona have walls $1-3 \mu \mathrm{m}$ thick with type 9 villar protrusions, ultrastructure of a distinct thin-walled sarcocyst (0.5-0.7 $\mu \mathrm{m}$ thick) lacking villar protrusions, but instead exhibiting minute type 1 undulations on the sarcocyst wall, is described in this report. Parasites characterized from a sea otter infection were inferred to be related to, but distinct from, other species belonging to Sarcocys$t i s$, based on sequencing and phylogenetic analysis of a portion of the beta subunit of the plastid-encoded RNA polymerase gene.

Disease in a group of sea otters (Enhydra lutris) was recently attributed to infection with Sarcocystis neurona, a parasite that causes fatal neurologic disease in horses and other mammals (Dubey, Lindsay, Saville et al., 2001). Sea otters from the coast of California and Washington died of encephalitis associated with S. neurona schizonts (Rosonke et al., 1999; Lindsay et al., 2000, 2001; Miller et al., 2001). In addition, $S$. neurona sarcocysts were found in 2 other sea otters (Rosonke et al., 1999; Dubey, Rosypal et al., 2001). Parasites lacking the thick sarcocyst walls and elongated villar protrusions characteristic of $S$. neurona also have been observed in sea otters (in sea otter no. 2 of Dubey, Rosypal et al., 2001). To characterize this unidentified parasite better, transmission electron microscopy (TEM) was used to define its ultrastructure. To further aid future efforts to identify and diagnose sea otter infections, the platid-encoded beta subunit of RNA polymerase (rpoB) was amplified from infected sea otter tissue and compared with homologous sequences from $S$. neurona, $S$. falcatula, and $S$. lindsayi (Table I).

Two sarcocysts from a paraffin section of the skeletal muscle of sea otter were deparaffinized, postfixed in osmium tetraoxide, and processed for TEM examination. In 1- $\mu \mathrm{m}$ toluidine blue-stained sections, the sarcocysts measured $95 \times 60$ and $110 \times 65 \mu \mathrm{m}$. The sarcocyst wall was $<1 \mu \mathrm{m}$ thick without visible villar protrusions (Fig. 1). Septa were indistinct.

Under TEM the sarcocyst wall was found to be $0.5-0.7 \mu \mathrm{m}$ thick and bore minute, electron-dense undulations located at irregular intervals (Fig. 2A, B). The maximum observed width of the sarcocyst wall at the point of infolding and beginning of septa was $1.0 \mu \mathrm{m}$. Only bradyzoites were seen, and 3 longitudinally cut bradyzoites were 5.0$5.7 \times 1.6-1.9 \mu \mathrm{m}$ in size. Rhoptries were prominent, and their bulbous blind end was sometimes turned toward the conoidal end (Fig. 2A). The micronemes were located in the anterior half of the bradyzoite. Thus, the thin-walled sarcocysts in the present report were ultrastructurally distinct from those of $S$. neurona, which typically bear walls $1-3 \mu \mathrm{m}$

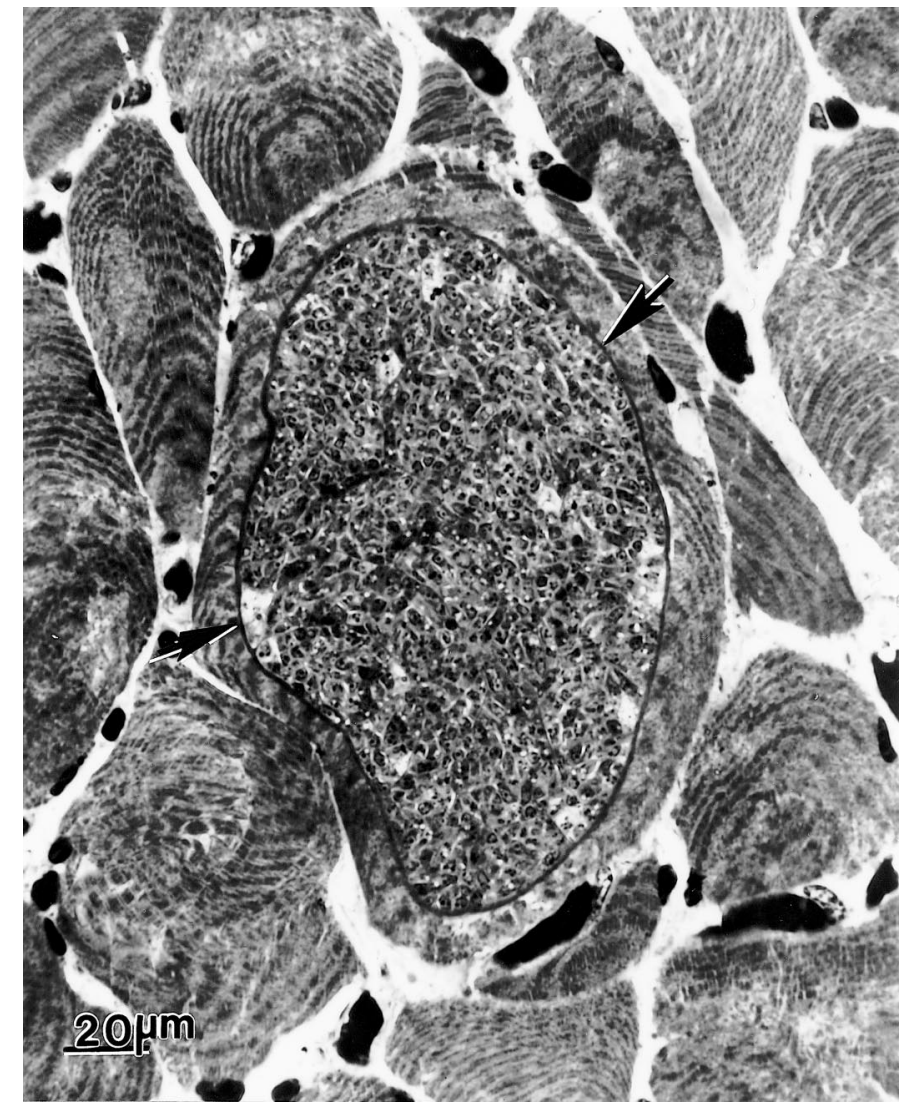

FIGURE 1. Section of sea otter skeletal muscles showing a Sarcocystis sp. sarcocyst. Note the thin sarcocyst wall (arrows). Toluidine blue stain.

in thickness featuring prominent villar type 9 protrusions (Dubey et al., 1989; Dubey, Lindsay, Fritz et al., 2001).

In the initial report of an unidentified sarcocyst in the musculature of an encephalitic sea otter, villi were present on the sarcocyst walls,

TABLE I. Sources of parasite isolates.

\begin{tabular}{lll}
\hline \multicolumn{1}{c}{ Name } & \multicolumn{1}{c}{$\begin{array}{c}\text { Host species, } \\
\text { locale, and reference }\end{array}$} & $\begin{array}{c}\text { GenBank } \\
\text { accession }\end{array}$ \\
\hline Sarcocystis lindsayi & Didelphis albiventris; Brazil; Dubey, Rosenthal, and Speer (2001). & AY164997 \\
Sarcocystis sp. & Enhydra lutis; Washington; Dubey, Rosypal, Rosenthal et al. (2001). & AY164998 \\
S. falcatula & Didelphis albiventris; Argentina; Dubey, Rosenthal, and Speer (2001). & AY164999 \\
S. neurona & Didelphis albiventris; Brazil, SN 35-OP; Dubey Lindsay, Kerber et al. (2001). & AY165000 \\
S. falcatula-like & Didelphis marsupialis; Argentina; Dubey, Lindsay, Rosenthal et al. (2001). & AY165001 \\
\hline
\end{tabular}




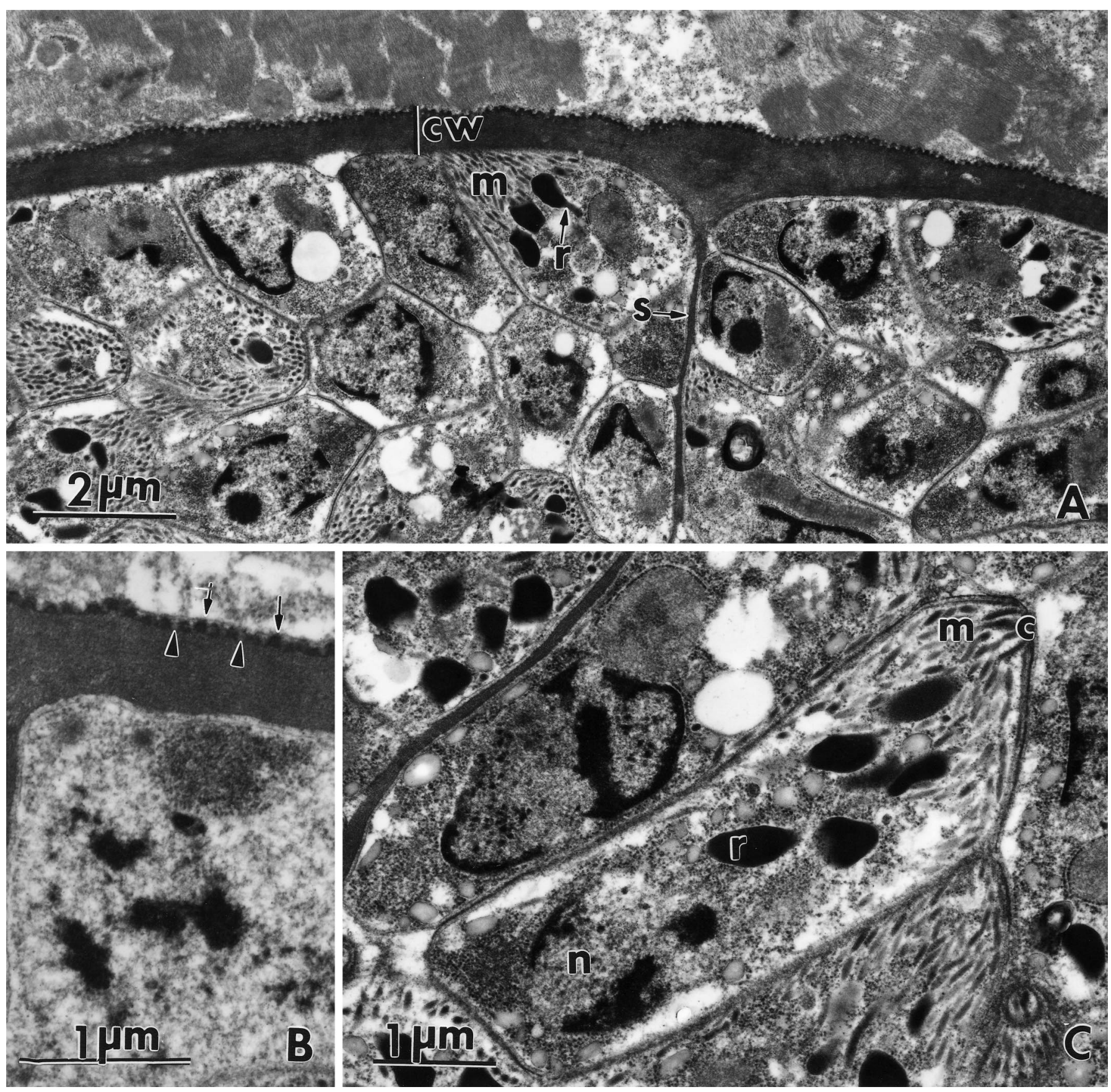

FIGURE 2. Transmission electron micrograph of a mature sarcocyst from the skeletal muscle of the sea otter. A. Note the thin cyst wall (cw) with minute protrusions. The ground substance is homogenous without microtubules and continues into the sarcocyst interior as septa (s). All organisms present are bradyzoites. A rhoptry ( $\mathrm{r}$ ) in 1 bradyzoite has its bulbous end turned toward the conoidal end. Also note numerous micronemes $(\mathrm{m})$ toward the conoidal end. B. Higher magnification of the sarcocyst wall. Note the minute protrusions on the sarcocyst wall, interrupted at irregular intervals (arrow heads). C. Longitudinal section of a bradyzoite showing the conoid (c), micronemes (m), rhoptries (r), and terminal nucleus (n).

but autolysis obscured additional ultrastructural details (Rosonke et al., 1999). Dubey, Rosypal et al. (2001) described the ultrastructure of $S$. neurona sarcocysts in skeletal muscle of a sea otter that had died of $S$. neurona-associated encephalitis. Only sarcocysts resembling those of immature S. neurona were found in the encephalitic sea otter (sea otter no. 1 of Dubey, Rosypal et al., 2001). However, in the musculature of a second sea otter described by Dubey, Rosypal et al. (2001), light microscopy indicated that there were at least 2 additional types of sarcocysts; thin-walled sarcocysts, possessing septa but lacking villi, were distinct from the third type of sarcocyst. The third type of sarcocysts were thick-walled, with 7- $\mu \mathrm{m}$ villar protrusions, and were found in the tongue and not in the skeletal muscle. In the present report, using TEM, the presence of a structurally distinct, thin-walled sarcocyst was confirmed. Whether these sarcocysts correspond to those illustrated previously by Dubey, Rosypal et al. (2001) cannot be known with certainty because only 2 sarcocysts were examined ultrastructurally and because the true diversity of this mixed, natural infection is undefined.

DNA was extracted from sea otter isolate and used as a template in 


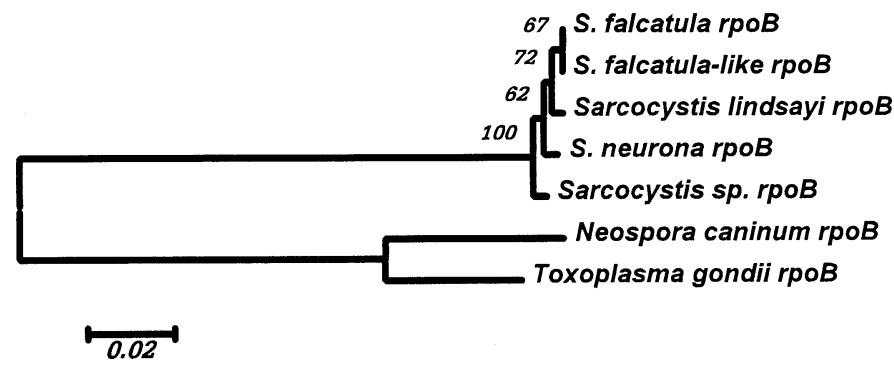

FIGURE 3. Midpoint-rooted neighbor-joining tree reconstructed from variation in the rpoB B gene. Kimura 2-parameter distances were calculated for each pair of sequences. The percentage of bootstrap replicates $(\mathrm{n}=1,000)$ in which a given node was recovered is indicated. Five hundred base pairs of the rpoB gene were sequenced from Sarcocystis sp. and from representatives of $S$. neurona, S. falcatula, and $S$. lindsayi in the sea otter (see Table I for details on isolates). The Neospora caninum and Toxoplasma gondii homologs were obtained from GenBank (accession nos. AF095904 and AF138960, respectively).

a polymerase chain reaction (PCR) by using degenerate primers designed to amplify the rpoB gene, encoded by the plastid genome of apicomplexans-primers F1 (5'- gcg gtc cca aaa ggg tca gtg gat atg atw twt gaa gat gc) and R3 (5'- gcg gtc cca aaa ggg tca gtc ctt tat ktc cat rtc t). The resulting 504-bp PCR products were directly sequenced using BigDye chemistries and an ABI 3100 automated fluorescent sequencer. Homologous sequences were characterized from isolates of $S$. neurona, S. falcatula, and S. lindsayi, the origins of which are summarized in Table I. These were aligned to each other and to homologs from Neospora caninum and Toxoplasma gondii by using CLUSTAL W 1.8 (Thompson et al., 1994), available on the bioinformatics server of the Baylor College of Medicine. Relationships of these sequences were investigated by constructing a gene genealogy by calculating $\mathrm{Ki}-$ mura 2-parameter distances from 1,000 bootstrap replicates of the alignment and using the Neighbor-Joining algorithm using MEGA 2.1 (Kumar et al., 2001).

The rpoB sequence obtained from the otter isolate was placed as a basal member of a clade that also contained the other examined isolates belonging to Sarcocystis but that included neither $N$. caninum nor $T$. gondii (Fig. 3). Concordant topologies were obtained when the minimum evolution and maximum parsimony criteria were used (data not shown). Several nucleotide substitutions distinguish this otter specimen from the isolates representing other species of Sarcocystis. In contrast, the rpoB of isolates representing $S$. falcatula are comparatively homogeneous. Thus, morphological and genetic evidence indicates that sea otters, in addition to being at the risk of exposure to S. neurona parasites, serve as host to at least 1 other species of parasites belonging to the genus Sarcocystis.

\section{LITERATURE CITED}

Dubey, J. P., D. S. Lindsay, D. Fritz, ANd C. A. Speer. 2001. Structure of Sarcocystis neurona sarcocysts. Journal of Parasitology 87: $1323-1327$.
, C. E. Kerber, N. Kasai, H. F. J. Pena, S. M. Gennari, O. C. H. Kwok, S. K. Shen, and B. M. Rosenthal. 2001. First isolation of Sarcocystis neurona from the South American opossum, Didelphis albiventris, from Brazil. Veterinary Parasitology 95: $295-304$.

- B. M. Rosenthal, C. E. Kerber, N. Kasai, H. F. Pena, O. C. Kwok, S. K. SHEn, AND S. M. Gennari. 2001. Isolates of Sarcocystis falcatula-like organisms from South American opossums Didelphis marsupialis and Didelphis albiventris from Sao Paulo, Brazil. Journal of Parasitology 87: 1449-1453.

- W. J. A. Saville, S. M. Reed, D. E. Granstrom, and C. A. SPEER. 2001. A review of Sarcocystis neurona and equine protozoal myeloencephalitis (EPM). Veterinary Parasitology 95: 89-131.

- B. M. Rosenthal, AND S. SpeER. 2001. Sarcocystis lindsayi $\mathrm{n}$. sp. (Protozoa: Sarcocystidae) from the South American opossum, Didelphis albiventris from Brazil. Journal of Eukaryotic Microbiology 48: 595-603.

- A. C. Rosypal, B. M. Rosenthal, N. J. Thomas, D. S. LindSay, J. F. Stanek, S. M. Reed, And W. J. A. Saville. 2001. Sar cocystis neurona infections in sea otter (Enhydra lutris): Evidence for natural infections with sarcocysts and transmission of infection to opossums (Didelphis virginiana). Journal of Parasitology 87: $1387-1393$

- C. A. SPEer, AND R. FAYer. 1989. Sarcocystosis of animals and man. CRC Press, Boca Raton, Florida, $215 \mathrm{p}$.

Kumar, S., K. Tamura, I. B. Jakobsen, and M. Nei. 2001. MEGA2: Molecular evolutionary genetics analysis software. Bioinformatics 17: $1244-1245$.

Lindsay, D. S., N. J. Thomas, And J. P. Dubey. 2000. Biological characterization of Sarcocystis neurona from a Southern sea otter (Enhydra lutris nereis). International Journal for Parasitology 30: 617624

, A. C. Rosypal, And J. P. Dubey. 2001. Dual Sarcocystis neurona and Toxoplasma gondii infection in a Northern sea otter from Washington state, USA. Veterinary Parasitology 97: 319-327.

Miller, M. A., P. R. Crosbie, K. Sverlow, K. Hanni, B. C. Barr, N. Kock, M. J. Murray, L. J. Lowenstine, and P. A. Conrad. 2001. Isolation and characterization of Sarcocystis from brain tissue of a free-living southern sea otter (Enhydra lutris nereis) with fatal meningoencephalitis. Parasitology Research 87: 252-257.

Rosonke, B. J., S. R. Brown, S. J. Tornquist, S. P. Snyder, M. M. GARNER, AND L. L. Blythe. 1999. Encephalomyelitis associated with a Sarcocystis neurona-like organism in a sea otter. Journal of the American Veterinary Medical Association 215: 1839-1842.

Thompson, J. D., D. G. Higgins, and T. J. Gibson. 1994. CLUSTAL $\mathrm{W}$ : Improving the sensitivity of progressive multiple sequence alignment through sequence weighting, positions-specific gap penalties and weight matrix choice. Nucleic Acids Research 22: 46734680 .

\section{Morphology Is Not a Reliable Tool for Delineating Species Within Cryptosporidium}

Abbie Fall, R. C. Andrew Thompson, Russell P. Hobbs, and Una Morgan-Ryan ${ }^{\star}$, Division of Veterinary and Biomedical Sciences, Murdoch University, Perth, Western Australia 6150, Australia. * To whom correspondence should be addressed. e-mail: unaryan@central.murdoch.edu.au

ABSTRACT: Within the coccidia, morphological features of the oocyst stage at the light microscope level have been used more than any other single characteristic to designate genus and species. The aim of this study was to conduct morphometric analysis on a range of Cryptospo- ridium spp. isolates and to compare morphological data between several genotypes of $C$. parvum and a second species $C$. canis, as well as a variation within a specific genotype (the human genotype), with genetic data at 2 unlinked loci (18S ribonucleic deoxyribonucleic acid and HSP 